\title{
ENERGY SAVING CONTROL OF SERIES EXCITATION MOTOR
}

\author{
Yuri N. Dementyev ${ }^{1,}{ }^{*}$, Kirill N. Negodin ${ }^{1}$, Min Tu Aung ${ }^{2}$, and Viktor I. Susdorf ${ }^{2}$ \\ ${ }^{1}$ National Research Tomsk Polytechnic University, 634050, Tomsk, Russia \\ ${ }^{2}$ State Technical University, Komsomolsk-na-Amure, Russia
}

\begin{abstract}
Losses optimization in transients with series excitation motor (SEM) control just by control, at that controlled value is input voltage of SEM, is considered in this paper. Algorithm of optimal control of SEM, that allows to define SEM control optimality in relation of production by method of dynamic programming with eliminations of current and voltage, is suggested. It is defined, that optimal control in SEM transients in relation of production is same as optimal control with energy losses minimum
\end{abstract}

\section{Introduction}

The problem of controlling series-wound motor in terms of optimization of its energy still remains relevance for researchers to these days. Although the widespread use of serieswound motor in the traction electric drive, electrical hand tools and household appliances, theoretical investigations are extremely rare. We can notice the works of Russian scientists devoted to the theoretical and practical improvement of energy performance of electric drives with single phase collector series excitation motor: V.P. Klimov, N.F. Elias, V.G. Kagan, G.V. Lebedeva, L.I. Malinina, Y.P. Petrov, M.H. Bellman and also T. Fujimaki, G.K. Dubey and others $[1,2,3,4,5]$, who correctly point out that the classical variation methods for finding the optimal control of series-wound motor does not provide direct solutions. One approach for finding the optimal control of collector series excitation motor is described in $[2,4]$. Specifically, the following divergent objectives for controlling drives were considered:

a) maximum productivity by limiting the electric heat losses in the motor and specified motion time;

b) minimum loss at specified productivity and time;

c) maximum performance with constraints on the phase coordinates movement and heat loss;

It is known that the principle of reciprocity isoperimetric problem, they have a common solution.

\section{Study technique}

\footnotetext{
*Corresponding authors: dementev@tpu.ru
} 
Modern technical equipment allows providing regulation of the input electrical parameters of the electric motor in such a way as to provide a current waveform and its spectral composition to minimize the energy loss associated with the resolution of control. Based on this, consider the control of series-wound motor with "smooth" power supply. Losses from hysteretic currents, mechanical losses and other kinds of losses, the struggle of which is the improvement of technical equipments, in our opinion, quite well - we leave out the present article and ask the optimization of losses in transient states only by control. The control parameter is obviously the input voltage of the motor.

Classically the optimal control problem is solved for speed control drive in the increment of speed, in the formulation of minimum losses: it is required to find a function $i(t)$, providing a minimum loss of $\mathrm{Q}$.

When using the Pontryagin maximum principle, in general case the solution of the problem can be obtained in the form $[3,6,7]$ :

$$
i(t)=\left\{\begin{array}{llr}
+i_{\max } & \text { where } & o \leq t \leq t_{1} \\
\sqrt{M_{c}} & \text { where } & t_{1} \leq T
\end{array}\right.
$$

The parameters of transient process depend on the limits of dynamic properties of drive and mainly depend on the restrictions imposed on it (especially the maximum permissible value of the current, the voltage and current slew rate), which determine the permissible rate of acceleration - deceleration. Since the electromagnetic torque and the heat losses are proportional to the square of the motor current, then in equation 1 logically substitute the maximum current value. This corresponds to the optimality criterion, and allows proceeding to consideration of the physics of energy processes, where the energy loss due to heating depend on the time: $Q=\Delta P . t=i^{2} . t$.

Due to the fact that the rectangular dynamic torque cannot be ensured in practice, we find the optimal control of series-wound motor from the point of view of performance using dynamic programming with constraints on voltage and current. Algorithm for solving the problem is shown in Figure 1 (symbols are common).

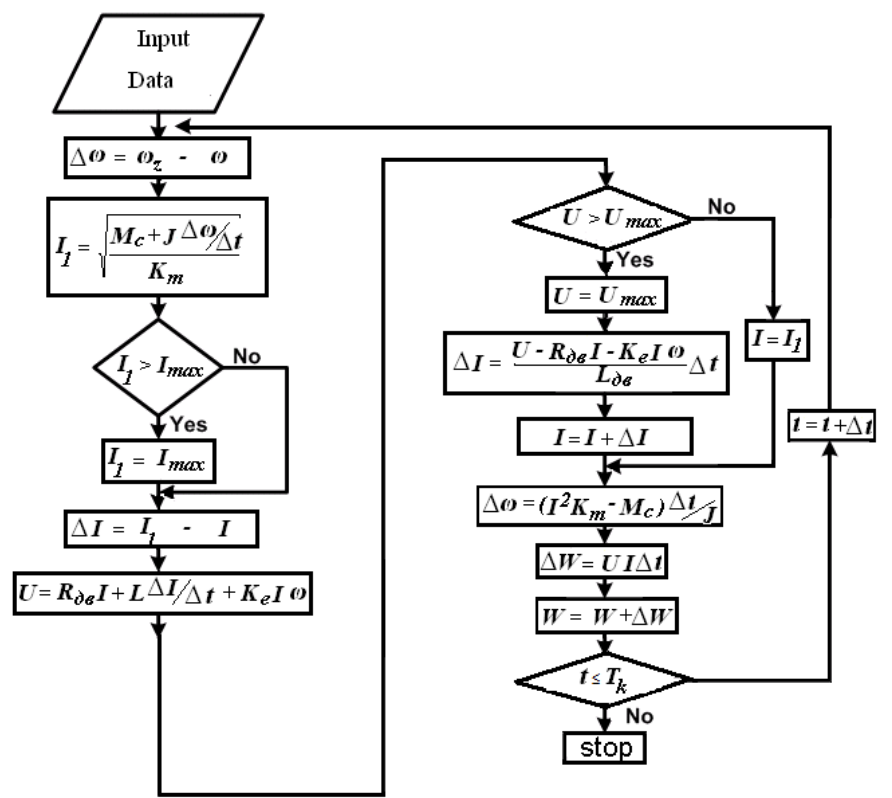

Fig. 1. Optimal control algorithm of series-wound motor. 


\section{Experimental results}
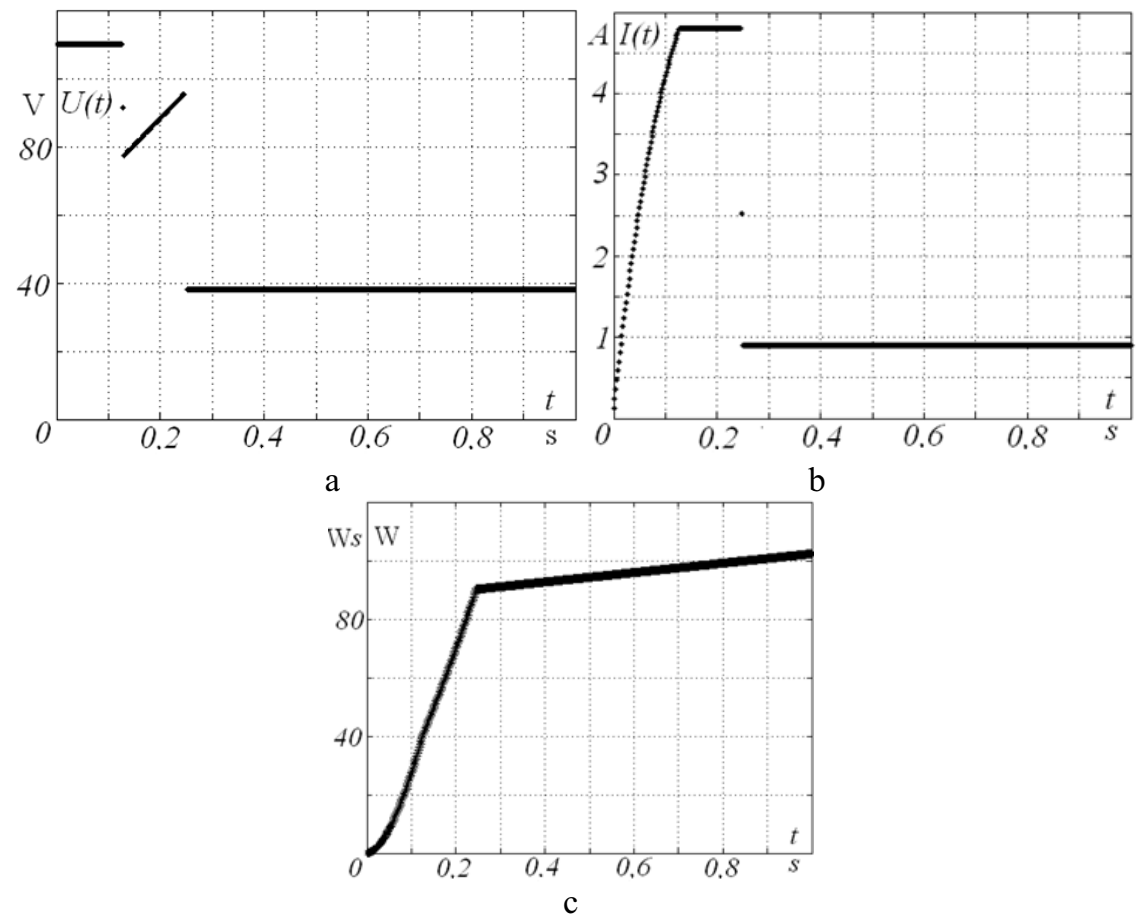

Fig. 2. The result of the calculation is shown in Figure 2 (a, b, c).

For comparison, figures 3 . $\mathrm{a}$ and $\mathrm{b}$ shows the same characteristics of the same motor for direct start in the absence of restrictions.

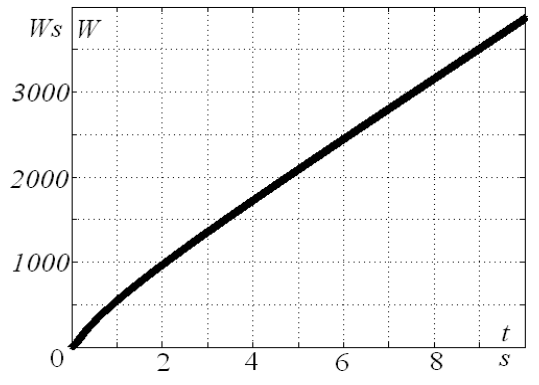

a

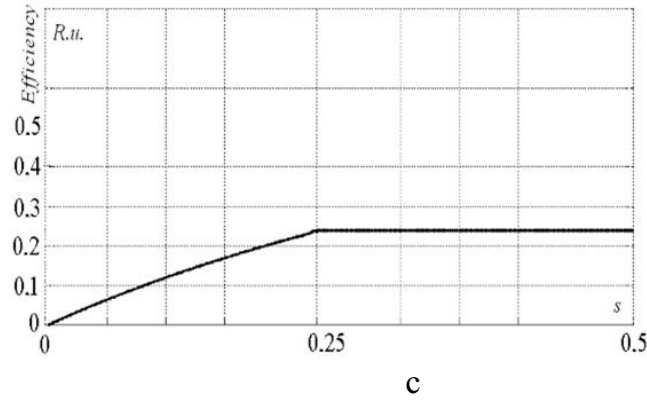

Fig. 3. Characteristics for direct start.
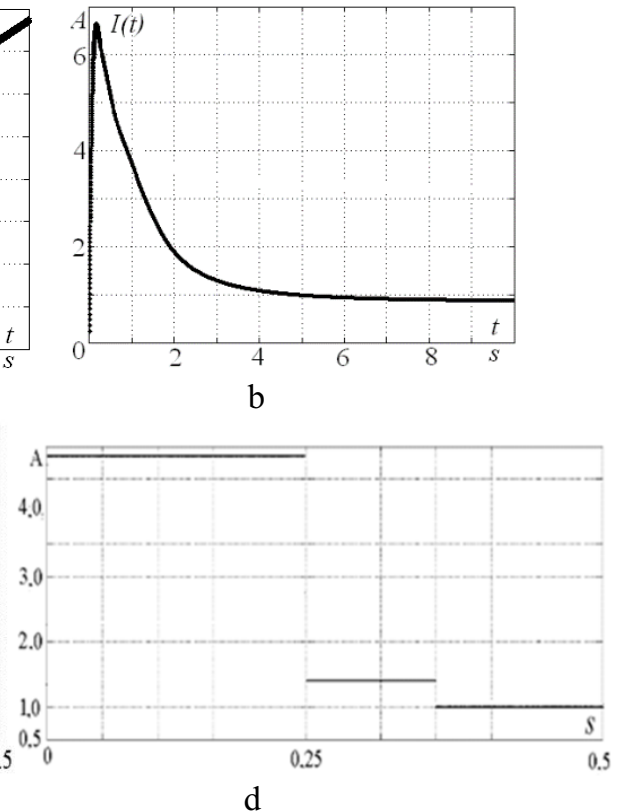
Comparative analysis of the characteristics shown in figure 3 and 4 shows that the time of transition ( $9 \mathrm{~s}$ vs $0.25 \mathrm{~s}$ ) as consumed during the transition process of electric energy $(3250 \mathrm{~W}$ vs $90 \mathrm{~W})$ differs in 36 times.

Figure $3 \mathrm{c}$ and $\mathrm{d}$ shows the current and efficiency curve of electric drive, which reduces the load on the shaft by $50 \%$ for 0.3 seconds in the transient process. From the characteristics it shows that the maximum efficiency is achieved when the output speed is stable, so the duration of the transient process negatively impact on the energy sector. In this plot with a maximum current value corresponds to the maximum rate of speed change and hence minimizes the operating time with a relatively low efficiency.

The above illustration is consistent with the known results of research $[2,3,6,8,9]$, and allows concluding that for the series-wound motor in the transient optimum control in terms of performance is the optimal control of minimum energy losses.

\section{Conclusion}

According to the experimental results, the following conclusions can be made:

- Created a new algorithm of synthesis of optimal control with constraints on the coordinates of movement.

- Set numeric energy efficiency optimal control of engine serial excitation

\section{References}

1. T. S. Bukanova, L. A. Steshina, A. B. Savinih, Mehatronika, avtomatizaciya, upravlenie, 10, 48 (2009)

2. A. S. Meshkov, Nauchno-issledovatelskih rabot finalistov konkursa aspirantov I molodih uchenih v oblasti energosberezheniya v promishlennosti, g. Novocherkassk, 49 (2010)

3. A. E. Alehin, Yu. N. Dementyev, B. I. Susdorf, DC Electric Drive with series excitation motor. License RUS 1676418 (1990)

4. A. S. Meshkov, V. I. Susdorf, Y. N. Dementyev, D. A. Kaftasyev, MATEC Web of Conferences, 19, (2014)

5. B. V. Suhinin, V. V. Surkov, S. A. Ciruh, E. I. Feofilov, Optimal in accuracy (speedwork, energyefficiency) control of electromechanical objects, (Learning edition, Tula, 2014) [in Russian]

6. Yu. A. Shurigin, Elektronnie sredstva I sistemi upravleniya, 8 (2003) [in Russian]

7. M. V. Pronin, Electric drives and systems with electric machines and semiconductor converters, (Spb. 2004) [in Russian]

8. A. G. Ivanov, G. A. Belov, A. G. Sergeev, Control system of semiconductor converters, (2010) [in Russian]

9. A.E. Alehin, Yu. N. Dementyev, B.I. Susdorf, 6th Conferenc II, Budapest, 564 (1990) 